\title{
Using Online Peer Review through Discussion via Schoology to Enhance College Students' Proficiency in Argumentative Writing: A Case Study
}

\author{
Hasan Zainnuri ${ }^{1}$, Dewi Cahyaningrum ${ }^{1}$ \\ ${ }^{1}$ English Education Department, Faculty of Teacher Training and Education, Sebelas Maret \\ University \\ Jalan Ir. Sutami No. 36 A, Kentingan, Surakarta, Central Java, Indonesia.
}

\begin{abstract}
Due to its difficulties, many students find that writing is challenging and many teachers struggle to find effective methods to teach the skill. The primary aim of this study is to review the use of Schoology, a Learning Management System (LMS) with its peer review and discussion feature to enhance the proficiency of students in argumentative writing. The method used in this study is a case study. Subjects of this research is the second semester college students of English Education Department in Sebelas Maret University. In general, this paper reports the result of a case study research mainly talking about (1) how to enhance college students' proficiency in argumentative writing, (2) innovative teaching practice on argumentative writing for intermediate students by using the benefits of online peer review through discussion via Schoology.
\end{abstract}

Keywords: schoology; peer review; discussion; online; argumentative writing

\section{INTRODUCTION}

Language is the medium through which students can learn various skills, form their identities, and interact socially with others. Language is also the corner stone of the teaching and learning process (Bloom in Mira, 2004) [1]. Writing is a complex task involving the use and coordination of several cognitive processes. Writing is one of the most complex activities that involve grammar and semantic instruction. Teachers have always considered writing difficult to assess, measure, and analyze. Even in the $21^{\text {st }}$ century, writing is still perceived as a challenging task involving a wide range of abilities.

Argumentative writing teaching has too many benefits. It can support to develop students' critical thinking skills, which includes listening, reading, and writing skills that can support useful in both the professional and academic realms. It gives students a firm basis in logic that they may not receive in other classes. Moreover, it can assist students to be aware of persuasion and argument role in daily lives. 
Although this is a very complicated unit with many complex ideas, the benefits for our students are clearly significant with the difficulty.

Accompanied by the need to improve students' writing skills is the need to increase their proficiency level in English language. Bindu (2014) clearly stated that English value has expanded enormously in the past decade due to increasing demand of English language in jobs, growing social mobility and global competitiveness so that English becomes the most widely spoken languages in the world.

One of the characteristics of active learning is student engagement. Active learning strategies include problem-based inquiry, service learning, facilitated classroom discussion, and expository or persuasive writing. Student engagement is generally considered to be among the better predictors of learning. The premise is deceptively simple, perhaps self-evident: The more students study or practice a subject, the more they tend to learn about it. Likewise, the more students practice and get feedback on their writing, analyzing, or problem solving, the more adept they should become [2].

One of the popular learning management systems gaining popularity nowadays in the field of blended or online learning is Schoology. The researcher would like to investigate on the possibility of using the said LMS, especially on the use of discussion feature, in the effective delivery of argumentative writing lessons among college students in the university.

\section{METHOD OF THE RESEARCH}

This research was conducted in Paragraph Development class of English Department, Faculty of Teacher Training and Education, Sebelas Maret University. Subject of this research was the second semester students of academic year 2016/ 2017. This study used a qualitative methodology and Denzin and Lincoln's (1994) constructivist-interpretive approach to provide insight into "...the complex world of lived experience from the point of view of those who live it" [3-4]. A case study approach seemed appropriate as, according to Creswell (2013), “...case study research involves the study of an issue explored through one or more cases within a bounded system"'[5].

In this research, the researcher sought to gain an in-depth understanding of the case by collecting multiple forms of data in the form of events and documents [5]. Besides, the research data were collected using qualitative method. There are data collection techniques, namely document analysis, interview, and non- participant observation. The technique used in analyzing the data is qualitative data analysis. In this research, the steps in analyzing the data in qualitative data analysis are as follow: (1) data reduction, (2) data display, (3) conclusion drawing and verification [6]. 


\section{RESULT AND DISCUSSION}

Schoology, a collaboration and learning tool, is a web based learning environment that will give students, teachers, and parents access to class materials and information via the internet, whether through website or Schoology application, in a full day. Schoology is free and allows online collaboration in a user friendly and secure environment for teacher to teacher, teacher to student, and even student to student. It provides the possibilities of integrating this collaboration and learning tool to customize learning for each student [7].

The design of Facebook is similar with Schoology in which messages are sent, conversations take place, statuses can be updated and information are shared within a classroom network as well as other media. Schoology involves two main contexts, namely academic information exchange and interactive communication. The first aspect is teacher can deliver academic information to students. In Schoology, students are able to access their assignments, grades, teaching materials, attendance records, and teacher feedback on electronically-submitted task. Communication between teachers and students increased by the access to this information and holds students academic responsibilities. The second aspect that Schoology has capitalized on is teachers can make collaborative groups, discussion questions, or assignments that provide students and their teachers a dynamic interaction. For example, students participating in writing assignment can ask questions and post comments about classmates' work. They can also provide feedback on each of their friends writing. Teachers can monitor these discussions and participate in by giving corrective feedback of their assignment [8].

\section{Innovative Teaching Practice on Argumentative Writing}

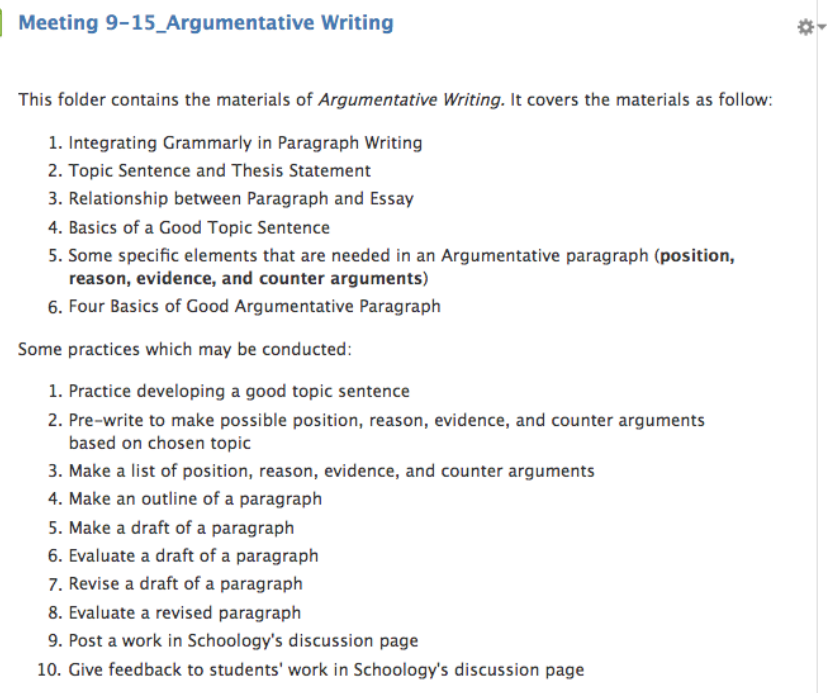

Figure 1. Teaching Instruction in Teaching Argumentative Writing 
Figure 1, a screen shot taken from the writer's Schoology account, shows the content of teaching materials which then will be covered in the topic of argumentative writing. Materials which are included are 1) integrating Grammarly in paragraph writing, 2) topic sentence and thesis statement, 3) relationship between paragraph and essay, 4) basics of a good topic sentence, 5) some specific element that are needed in an argumentative writing, and 6) four basics of good argumentative paragraph. All of those materials are explained by the lecturer by using Project Based Learning (PBL) method of teaching. It means the students are asked to do a final assignment as a project which is a final writing of argumentative essay. The steps on doing the PBL are described in the following paragraph.

First, all the materials in Schoology are explained by the lecturer in seven meetings. Students were asked to do some activities in the form of discussion and assignment in Schoology as can be seen in the Figure 1 as follows:

1. Practice developing a good topic sentence

2. Pre-write to make possible position, reason, evidence, and counter arguments based on chosen topic

3. Make a list of position, reason, evidence, and counter arguments

4. Make an outline of a paragraph

5. Make a draft of a paragraph

6. Evaluate a draft of a paragraph

7. Revise a draft of a paragraph

8. Evaluate a revised paragraph

9. Post a work in Schoology's discussion page

10. Give feedback to students' work in Schoology's discussion page.

Students were asked to do peer review through discussion activities for all of the items above in their own Schoology account. On the discussion page, the lecturer will give evaluation and score for the participation and engagement students have during discussion. Some assignments in the form of discussion activities used by the lecturer to teach Argumentative Writing are shown in the Figure 2 below. 


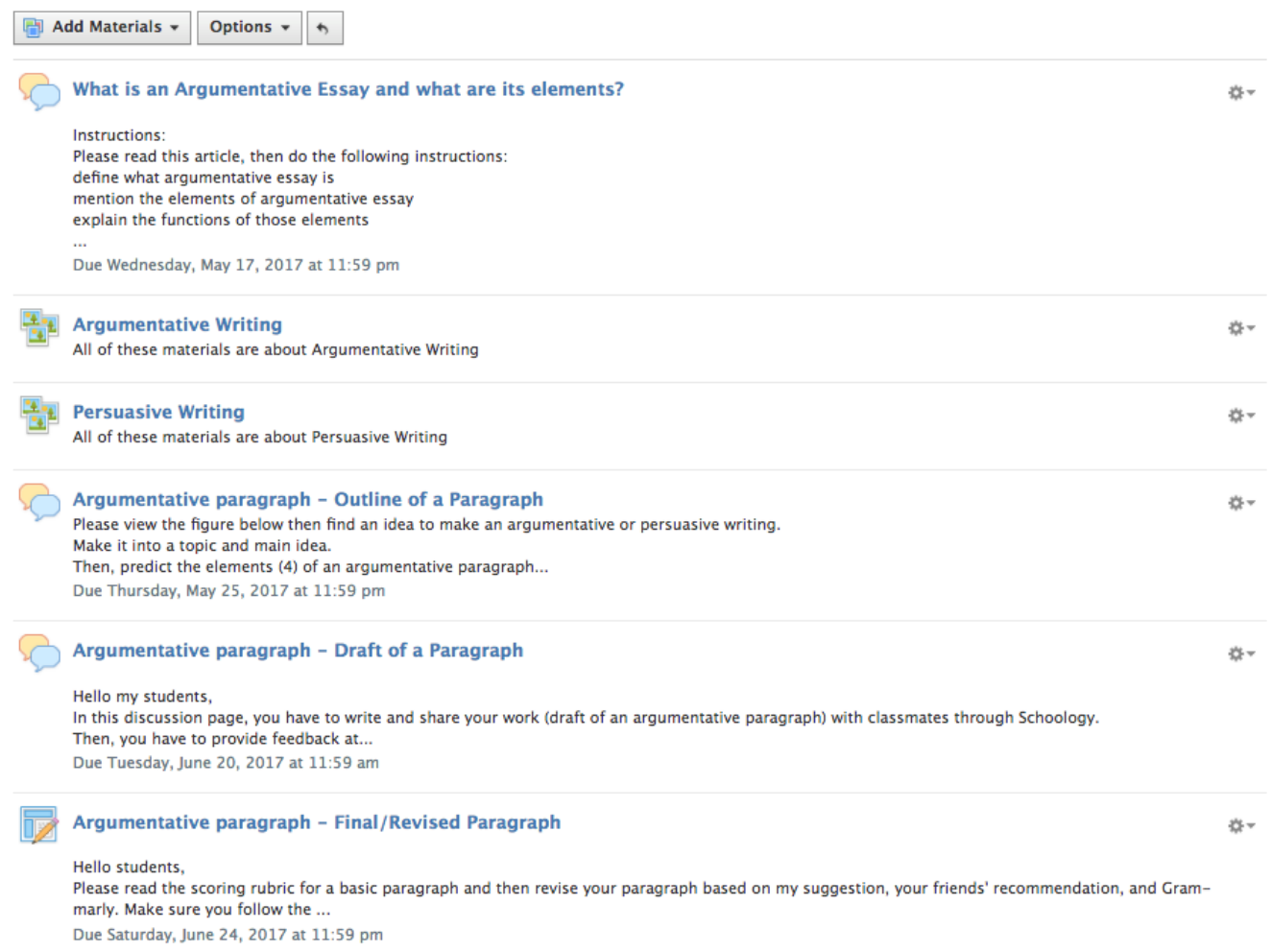

Figure 2. Assignments and Discussion Activities to Teach Argumentative Writing

In the discussion assignment of What is an argumentative essay and what are its elements?, argumentative paragraph - outline of a paragraph, and argumentative paragraph - draft of a paragraph; students were asked to get involved in those activities by giving peer review such as feedbacks, comments, and suggestions to their friends' postings or works. Peer review activities through discussion via Schoology can be seen in Figure 3 below. 


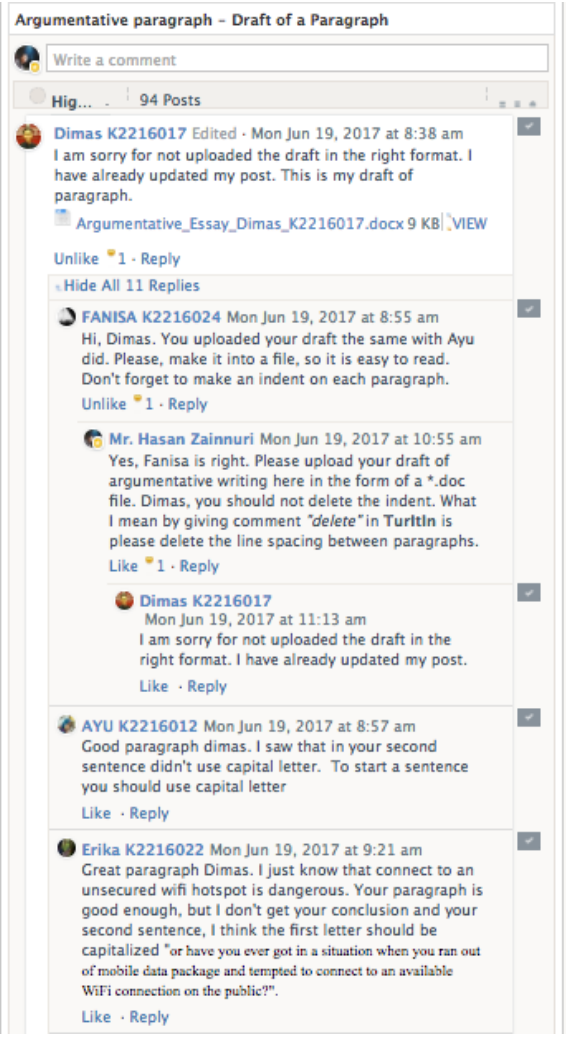

5 Majid K2216010 Mon Jun 19, 2017 at 9:23 am it is a great paragraph dimas, but maybe you can add some definition about wifi because not everyone understands about wifi and some kind of things that related to it.

Like - Reply

Desy K2216016 Mon Jun 19, 2017 at 10:00 am Good job, Dimas. Same as Fanisa's comment, you should make your paragraph into a file and don't forget to indent your beginning of each paragraph.

Like - Reply

ARUM K2216008 Mon Jun 19, 2017 at 10:16 am Good paragraph, Dimas. maybe you should check your typing and format of your paragraph before you submit

Like $\cdot$ Reply

AlifViana K2216005 Mon Jun 19, 2017 at 10:39 am Nice paragraph Dimas, but I think you should upload your paragraph into file. And you present nice hook and interesting topic so the reader will be more curious to read your essay. It is really good that you present daily life situation, this is really useful.

Like · Reply

Denita K2216015 Mon Jun 19, 2017 at 11:11 am Good Dimas, but $i$ think you should add indent and reduce space between paragraph Like - Reply

Adib K2216002 Edited · Mon Jun 19, 2017 at 2:56 pm It's very interesting topic Dimas, by reading your paragraph. It will make the readers more careful in connecting their gadget to the unsecured public wifi. Like - Reply

Figure 3. Dimas's work and his friends' peer review

From the Figure 3 above, it can be seen that most of students provide peer review by leaving comments and giving their opinion about Wifi Connection, the topic Dimas choose as his draft of paragraph for this assignment. For example, Erika gave opinion that Wifi connection sometimes dangerous and Adib could be more careful in connecting his gadget to unsecured public Wifi. Moreover, students also gave peer review by leaving feedbacks and suggestions to Dimas such as uploading in the form of document file by Fanisa, giving advice about punctuation by Ayu and Erika, giving suggestion about indentation by Fanisa, Desi and Denita, and adding some definition about Wifi by Majid. Similarly, students gave peer review on Fanisa's work as can be seen in Figure 4 below. 


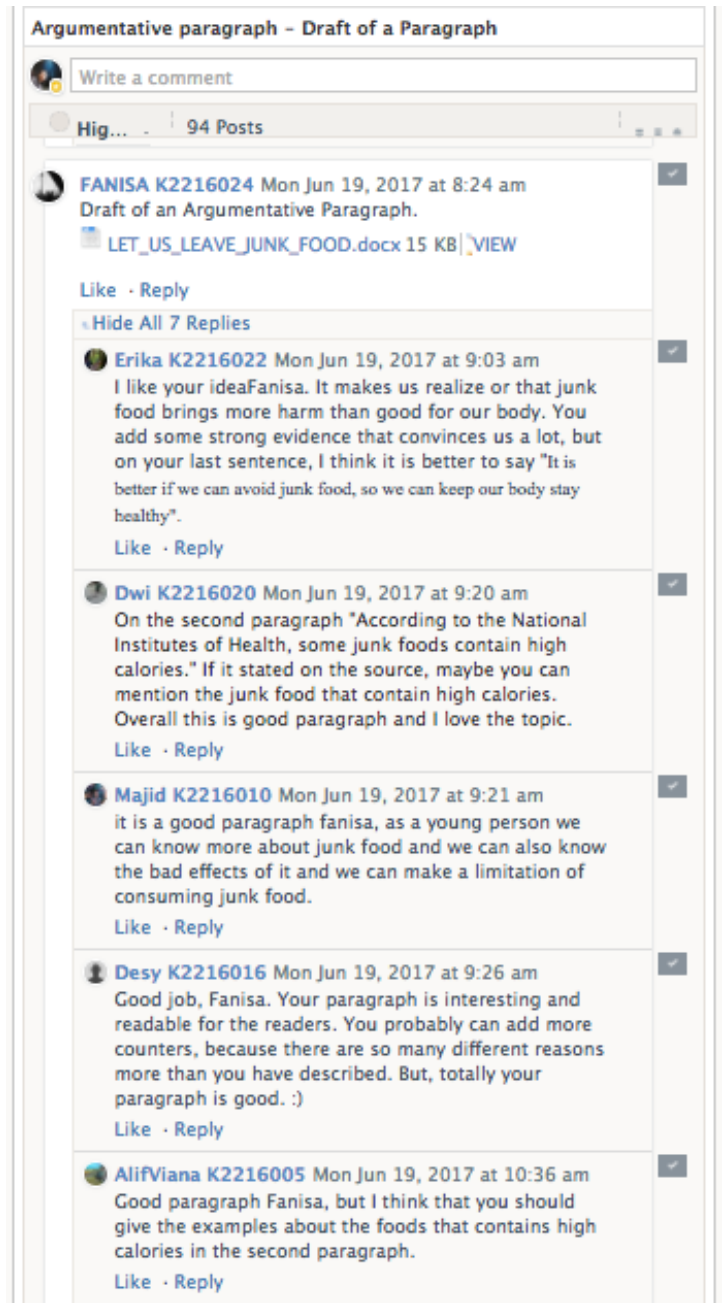

Figure 4. Fanisa's work and his friends' peer review

From the Figure 4 above, it can be seen that most of students provide peer review by leaving comments and giving their opinion about junk food, the topic Fanisa choose as her draft of paragraph for this assignment. For example, Erika liked Fanisa idea and gave opinion that junk food brings more harm than good for our body and Majid could know the bad effects of junk food. Likewise, students also gave peer review by leaving feedbacks and suggestions to Fanisa such as correcting grammatical errors by Erika, giving advice to add supporting sentences by Dwi, adding more counters by Desy, and giving more example about high calories food by Alifiana. 


\section{The Impact of Discussions on Student Engagement Discussions}

Discussions are one of the easiest and most effective tools for assessing students and engaging learners in conversations. Each discussion contains threaded commenting that allows students to respond to each other's comment. So while students are receiving feedback from their peers, they are gaining valuable formative feedback from the conversation.

Discussions provide chances to have practice on communication skills, critical thinking, contextual language, digital responsibility, and building relationships with teachers and classmates [9]. They also increase student engagement by way of authenticity, active participation, and student agency. Participation is one of those instructional strategies, straightforward, expected, and often quite successful at accomplishing a number of learning goals.

\section{Students' Perception on Using Schoology in the Argumentative Writing Class}

In an interview with highly motivated learners, they said Schoology LMS for the teaching of argumentative essay is accessible very fast through its downloadable mobile application. Moreover, the subjects revealed that using Schoology LMS made them more responsible and self-confident since the teacher does not tell when the materials will be uploaded exactly. Finally, the activities that students are assigned such as peer review and give feedbacks on their friends' work in the form of discussion activities have encouraged students to think more critically. Thus, it can be determined that online peer review through discussion via Schoology can support facilitate to enhance students' proficiency in higher education about argumentative writing. This statement is in line with the result of Sicat's experimental research which concludes that the LMS Schoology in addition to the traditional method of teaching can help facilitate in enhancing the college students' proficiency in Business Writing [10].

\section{Tips and Tricks for Creating Effective Class Discussions}

Discussion in Schoology courses provides some benefits for teachers and students. However, it is necessary to know the best practice to do such kind of activities. Here are a few tricks the writer have learned for making discussions more effective and engaging overall. First, encourage students to use different media such as audio and video to give an idea and peer review during discussion activities. Second, have students comment on each other's posts and lead the conversation. Third, ask students to clarify questions and issues for all participants as they arise. Fourth, model civility and respect and have students practice the same. Fifth, encourage conceptual risk taking to push critical thinking and build a climate of trust. 


\section{CONCLUSION}

Based on the results and discussion above, the researcher concludes that online peer review through discussion via Schoology can help facilitate in enhancing the college students' proficiency in Argumentative Writing by giving some activities in the form of discussion to ask students give peer review, feedback, comment, suggestion, and opinion to their friends' work. It is necessary to inform the students that the discussion activities will be evaluated and scored so that they will get involve and participate in every discussion. Then, a few tricks for making discussions more effective and engaging overall are encourage the use of different media, have students comment on each other's posts and lead the conversation, clarify questions and issues, ask students to respect, and encourage conceptual risk taking.

\section{REFERENCES}

[1] M. M. Alameddine and H. S. Mirza. 2016. "Teaching Academic Writing for Advanced Level Grade 10 English,” Procedia - Soc. Behav. Sci., 232:209-216.

[2] R. M. Carini, G. D. Kuh, and S. P. Klein. 2003. "Student Engagement and Student Learning: Testing the Linkages Student Engagement and Student Learning: How Can We Characterize the Linkages? Background".

[3] N. K. Denzin and Y. S. Lincoln. 1994. Handbook of qualitative research, vol. 1.

[4] T. A. Schwandt. 1994. "Constructivist, interpretivist approaches to human inquiry," Handb. Qual. Res., pp. 118-137.

[5] J. W. Creswell. 2013. Qualitative Inquiry and Research Design. Thousand Oaks, CA: Sage Publications.

[6] M. B. Miles and A. M. Huberman. 1994. Qualitative data analysis. Sage Publications.

[7] "What is Schoology? Farmington Schoology," 2014. [Online]. Available: https://sites.google.com/site/farmingtonschoology/what-is-schoology. [Accessed: 26-Jul2017].

[8] C. Manning, W. Brooks, V. Crotteau, A. Diedrich, J. Moser, and A. Zwiefelhofer. 2011. "Tech Tools for Teachers, By Teachers: Bridging Teachers and Students," Wisconsin English J. 53(1).

[9] M. Weimer, "10 Benefits of Getting Students to Participate in Classroom Discussions Faculty Focus," Fac. Focus. pp. 1-4.

[10] A. S. Sicat. 2015. "Enhancing College Students' Proficiency in Business Writing Via Schoology," Int. J. Educ. Res. 3(1): 159-178. 